\title{
Colorectal cancer screening: A guide to the guidelines
}

\author{
Douglas K Rex MD
}

DK Rex. Colorectal cancer screening: A guide to the guidelines. Can J Gastroenterol 1999;13(5):397-402. The two most recent guidelines for colorectal cancer screening are those of the Agency for Healthcare Policy and Research, and the American Cancer Society. The guidelines are similar in many regards and reflect current literature, consensus opinion and compromise between members of multidisciplinary panels. The emphasis of both guidelines is to increase the options available for colorectal cancer screening. Increasing choice should expand the attractiveness of colorectal cancer screening to more patients and physicians, and the development of guidelines should help compel payers to provide reimbursement for colorectal cancer screening. These guidelines are summarized and evaluated as they pertain to colorectal cancer screening.

Key Words: Colorectal cancer; Endoscopy; Fecal occult blood testing; Sigmoidoscopy

\section{Dépistage du cancer rectocolique : comment appliquer les directives}

RÉSUMÉ : Les deux plus récentes directives pour le dépistage du cancer rectocolique sont celles de l'Agency for healthcare Policy and Research et de l'American Cancer Society. Ces directives se ressemblent à beaucoup de points de vue et reflètent la littérature actuelle, l'opinion consensuelle et les compromis entre les membres des comités pluridisciplinaires. Ces deux documents soulignent la nécessité de multiplier le nombre d'options offertes pour le dépistage du cancer rectocolique. En multipliant les choix, on rend le dépistage rectocolique plus facile d'accès pour les patients et les médecins et la mise au point de directives devrait encourager les organismes subventionnaires à rembourser les tests de dépistage du cancer rectocolique. Ces directives sont résumées et évaluées en ce qui a trait au dépistage du cancer rectocolique.
$\mathrm{C}$ onvincing evidence of the effectiveness of fecal occult blood testing and sigmoidoscopy in reducing mortality from colorectal cancer has led a number of groups to publish statements or guidelines that endorse colorectal cancer screening $(1,2)$. These published statements, in conjunction with the new coverage for colorectal cancer screening for Medicare beneficiaries in the United States, have combined to make colorectal cancer screening the standard of care for medical practice in the United States in 1998. Hopefully, private insurers will feel compelled by these steps to provide coverage for screening. The percentage of eligible screenees in the United States who have been screened is still low. Major education efforts from the Centers for Diseases Control, the Digestive Disease National Coalition, individual gastrointestinal societies and patient advocacy groups are being undertaken to inform the public and primary care physicians about the importance of undergoing and carrying out colorectal cancer screening programs. Education combined with acceptable reimbursement are major factors that will drive increased use of screening. Malpractice litigation will be an additional factor that will increase physician compliance with offering screening and stimulate payers to provide coverage for screening.

Although the issue of whether screening works is considered settled, the issue of how screening should be done is evolving. Rigorous evidence of effectiveness exists only for

Indiana University School of Medicine, Director of Endoscopy, Indiana University Hospital, Indianapolis, Indiana, USA

Correspondence and reprints: Dr Douglas K Rex, Indiana University School of Medicine, 550 North University Boulevard, Room 300, Indianapolis, IN 46202, USA. Telephone 317-274-0912, fax 317-274-0975, e-mail drex@iupui.edu 
TABLE 1

\section{Options for screening average-risk persons: Agency for Health Care Policy and Research, and American Cancer Society guidelines}

Annual fecal occult blood test

Flexible sigmoidoscopy every 15 years

Annual fecal occult blood test plus flexible sigmoidoscopy every five years

Double contrast barium enema every five to 10 years

Colonoscopy every 10 years

American Cancer Society guidelines do not include fecal occult blood test by itself

fecal occult blood testing (randomized, controlled trials) and sigmoidoscopy (case-control studies). The United States Preventive Health Services Task Force has traditionally demanded very rigorous evidence before making a recommendation. Their earlier conclusion was that there was insufficient evidence to support colorectal cancer screening (3). Their most recent recommendation in 1996 was for annual fecal occult blood testing beginning at age 50 years; sigmoidoscopy was considered to be effective, although no interval was recommended (4). Fecal occult blood testing, however, has produced only modest mortality reductions of $15 \%$ to $33 \%$ in randomized, controlled trials (5-7). Sigmoidoscopy is also effective but has significant known limitations. Some screenees, recognizing the relative ineffectiveness of fecal occult blood testing and sigmoidoscopy, might prefer colonoscopy or perhaps double contrast barium enema (DCBE) as their screening test, although rigorous evidence for the effectiveness of these tests is lacking.

There is little understanding of which tests informed patients prefer (8). Presumably, there is a group of patients who are unable to overcome their personal distaste for having a device passed through their anus. For these people, fecal occult blood testing, although certainly imperfect, is a better choice than no screening at all. For those willing to have an invasive examination, it is uncertain whether there are clear preferences among flexible sigmoidoscopy, colonoscopy and barium enema. The choice likely depends on the screenee's perception of the relative importance of the effectiveness of the test, the need for sedation, the cost and the risk of complication.

Similarly, payers carefully weigh the relative risks, costs and effectiveness of sigmoidoscopy, fecal occult blood testing, colonoscopy and DCBE. Many payers likely offer fecal occult blood testing and sigmoidoscopy to average-risk patients because these procedures have the lowest up front costs and adequately meet the standard of medical care. Some payers, particularly those with a secure long term financial future and a stable patient base, might choose colonoscopy for average-risk persons, provided that they can negotiate the charge down to an acceptable level. Such payers recognize a long term cost savings over other strategies from more effective prevention of cancer.

The philosophy of the two most recently published major
TABLE 2

Types of data supporting the four screening modalities in the American Health Care Policy and Research, and American Cancer Society guidelines

\begin{tabular}{lccc}
\hline & $\begin{array}{c}\text { Randomized, } \\
\text { controlled trial }\end{array}$ & $\begin{array}{c}\text { Case-control } \\
\text { trial }\end{array}$ & $\begin{array}{c}\text { Cross-sectional } \\
\text { trial }\end{array}$ \\
\hline $\begin{array}{l}\text { Fecal occult blood } \\
\text { testing }\end{array}$ & $\checkmark$ & $\checkmark$ & $\checkmark$ \\
$\begin{array}{l}\text { Sigmoidoscopy } \\
\text { Colonoscopy }\end{array}$ & & \\
$\begin{array}{l}\text { Double contrast } \\
\text { barium enema }\end{array}$ & & $\checkmark$ \\
\hline
\end{tabular}

guidelines is to create a menu of choices for patients, physicians and payers to choose from. Clearly these choices are not equal from the perspectives of effectiveness, cost or risk; these differences provide the rationale for creating a menu of options.

The present review compares and contrasts the new guidelines from the Agency for Health Care Policy and Research (AHCPR) (1) and the American Cancer Society (ACS) as they pertain to screening (2). It is no accident that these guidelines are very similar. Clearly, the AHCPR guidelines significantly influenced the ACS guidelines. The present article serves to familiarize readers with the content of the guidelines and to point out for the reader specific strengths and weaknesses of the guidelines as perceived by the author.

\section{AVERAGE-RISK SCREENING: EVIDENCE TO SUPPORT SCREENING OPTIONS}

The average-risk population is defined as age 50 years or older and lacking other known risk factors. The guidelines from the AHCPR and ACS present a menu of options for average-risk screening (Table 1). The options are identical, except that the ACS declined to recommend fecal occult blood testing by itself, citing the relatively low mortality reductions that have been associated with its use. Table 2 shows the categories of data that support the screening modalities listed in the menus. For example, evidence supporting the use of fecal occult blood testing has been published in three randomized, controlled trials (5-7) and in a casecontrol study (9), and a large amount of cross-sectional data have been collected. Cross-sectional studies provide prevalence data, useful for describing the expected yield of a screening modality. For sigmoidoscopy, there are no data from randomized, controlled trials, but results from two strong case-control studies support its effectiveness $(10,11)$. These studies were largely performed using rigid sigmoidoscopy but have been widely extrapolated to flexible sigmoidoscopy. Cross-sectional data obtained by using flexible sigmoidoscopy from well over 10,000 patients have accumulated (12). Thus, the single time yield of screening flexible sigmoidoscopy in average-risk persons is well understood. For colonoscopy, data from randomized, controlled trials or case-control studies are not available. A large amount of 
cross-sectional data have accumulated, including data from five studies in average-risk persons (13-17), more than 10 studies $(12,18-28)$ in persons with a positive family history of cancer that does not meet the criteria for hereditary nonpolyposis colon cancer (HNPCC) and a number more in persons with a history of HNPCC (29-33). For DCBE, there are essentially no available data, although the original screening colonoscopy study in average-risk persons included 90 patients who also underwent DCBE (14). In one study of 738 persons using single contrast barium enema, the yield in screening populations was dramatically lower than has been detected using colonoscopy (34).

\section{OBSERVED INTERVALS}

Data from a randomized, controlled trial of fecal occult blood testing using rehydrated slides showed effectiveness at one year (5). In two studies that did not use rehydration, fecal occult blood testing at an interval of two years produced mortality reductions of $15 \%$ and $18 \%(6,7)$. The recommended interval in both guidelines was one year $(1,2)$.

With flexible sigmoidoscopy, the recommended interval is five years. The reason why the United States Federal Government provides coverage every four years is uncertain but may reflect previous guidelines that recommended flexible sigmoidoscopy at three- to five-year intervals, and the need to provide coverage at a single designated time point that was arrived at by averaging the three- to five-year interval. The longest observed interval in which a group of averagerisk asymptomatic individuals who were initially screened with flexible sigmoidoscopy and found to be negative, and then rescreened at a later date is 3.4 years (35). Collectively, these data support a very low yield of repeat screening at both one and three years, and support a move to a five-year interval. Evidence to support a longer interval also arises from the Kaiser case-control study of sigmoidoscopy, in which the protective effect of a sigmoidoscopy appeared to last for at least 10 years (10). The Prostate, Lung, Colorectal and Ovarian (PLCO) Cancer Screening Trial in the United States is about to begin accumulating observational data on flexible sigmoidoscopy at five years, which may support a move to even longer intervals.

\section{INTERVALS FOR DCBE AND COLONOSCOPY}

For DCBE, the recommended interval in the guidelines is five to 10 years. However, there are no observational data to support this because even the initial yield with barium enema in a screening population has been determined only in studies using single contrast barium enema and in no studies using DCBE. The intervals are based on estimates of sensitivity.

For colonoscopy, the recommended interval is 10 years. It is of interest that the interval for flexible sigmoidoscopy is five years and the interval for colonoscopy is 10 years because the strategies are fundamentally similar (endoscopic screening). The shorter interval for flexible sigmoidoscopy may reflect its lower cost. The longest observed interval in a screening population of individuals who were initially
TABLE 3

Fecal occult blood testing: Recommendation for use in clinical practice

Rehydration not recommended

Hemoccult II recommended

Avoid rectal examination testing

OK to test on $325 \mathrm{mg}$ acetylsalicylic acid/day or less, or on warfarin

If colonoscopy is negative, do not screen for five years

colonoscoped and were negative, and then recolonoscoped is 5.5 years (36). The incidence of new adenomas was $27 \%$, but the incidence of 'advanced' adenomas (those with villous or tubulovillous histology, high-grade dysplasia or size greater than $1 \mathrm{~cm}$ ) was less than $1 \%$. These data, plus those from the Kaiser case-control study (10) showing that the protective effect of a sigmoidoscopy is at least 10 years, helped lend support for the 10-year interval for colonoscopy.

\section{EFFECTIVENESS OF INDIVIDUAL OPTIONS: FECAL OCCULT BLOOD TEST}

In randomized, controlled trials, fecal occult blood testing on an annual to a semiannual basis reduced mortality by $15 \%$ to $33 \%$. Thus, ironically, while fecal occult blood testing provided the most rigorous evidence of the effectiveness of colorectal cancer screening, its overall impact was only modest. Fecal occult blood testing has the lowest up front cost of any screening method, but the downstream costs associated with evaluation of positive fecal occult blood tests and the cancer care costs associated with this strategy are substantial (37). A recent guideline made suggestions for the use of fecal occult blood tests in clinical practice (Table 3) (38). The negative predictive value of colonoscopy for cancer is very high. Thus, after a negative colonoscopy of the cecum by a competent endoscopist, with a good bowel preparation, all colorectal cancer screening should be stopped for at least five years.

\section{FLEXIBLE SIGMOIDOSCOPY}

The advantages of flexible sigmoidoscopy are its low cost, low risk, high accuracy over the area of colon examined, no need for sedation, easy preparation (enemas only in some practices) and a proven long protective effect (10). The only disadvantage is that it fails to examine the entire colon. The flexible sigmoidoscope reaches $50 \%$ to $60 \%$ of colon cancers in adenomas. Forty per cent of all colorectal cancers arise proximal to the splenic flexure (39), an area of the colon that is typically outside the reach of $60 \mathrm{~cm}$ flexible sigmoidoscopes. Only $25 \%$ of persons with cancer proximal to the splenic flexure have an adenomatous polyp distal to the splenic flexure. Thus, at least $30 \%$ of all persons undergoing screening flexible sigmoidoscopy have a normal examination (40). The overall effectiveness of combining fecal occult blood testing with flexible sigmoidoscopy remains uncertain, though estimates of mortality reduction of around $80 \%$ seem reasonable (37). 
TABLE 4

Recommendations for screening persons with a positive family history less than hereditary nonpolyposis colon cancer

\begin{tabular}{|c|c|}
\hline Family history & Recommendation \\
\hline $\begin{array}{c}\text { First degree relative with cancer } \\
\text { or adenoma diagnosed at age } \\
\text { younger than } 60 \text { years, or two } \\
\text { or more first degree relatives } \\
\text { with cancer and/or adenomas }\end{array}$ & $\begin{array}{l}\text { Colonoscopy every three to five } \\
\text { years beginning at age } 40 \\
\text { years, or } 10 \text { years younger } \\
\text { than youngest affected } \\
\text { relative, whichever comes first }\end{array}$ \\
\hline $\begin{array}{l}\text { Single first degree relative with } \\
\text { cancer or adenoma diagnosed } \\
\text { at age } 60 \text { years or older }\end{array}$ & $\begin{array}{l}\text { Same options as average-risk, but } \\
\text { begin screening at age } 40 \\
\text { years }\end{array}$ \\
\hline
\end{tabular}

\section{DCBE}

There are no data on the sensitivity of DCBE in a screening population. Data on sensitivity in symptomatic populations are quite mixed (41) and cannot be extrapolated to screening populations, which have a dramatically different spectrum of disease. The Office of Technology Assessment, an independent panel, estimated that the sensitivity of DCBE for large polyps and cancer in a screening population might be $70 \%$, although they included a calculation at $50 \%$ in their cost effectiveness model (41). The sensitivity may be in the range of $50 \%$, as was demonstrated in the National Polyp Study (42). This study is perhaps the best prospective blinded evaluation of the sensitivity of DCBE ever performed. Although the study was of a surveillance population, its disease spectrum and prevalence were very similar to those of a screening population. In that study, DCBE missed $50 \%$ of all adenomas greater than $1 \mathrm{~cm}$ in size. A particular difficulty with DCBE is that uncertainty regarding its sensitivity and the complete lack of observational data make determining intervals quite difficult. The recommended interval in the guidelines of every five to 10 years is a guess at the safe intervals, likely based on over-inflated estimates of sensitivity (1). In particular, the longer interval of 10 years seems ill advised. The specificity of barium enema in clinical practice is $85 \%$ to $90 \%$, so that short intervals result in a substantial portion of the screened population undergoing colonoscopy in any case.

\section{COLONOSCOPY}

The evidence to support colonoscopy centres principally on its effectiveness in preventing both colorectal cancer incident cases and mortality in adenoma cohorts $(43,44)$. The impact on mortality from colorectal cancer in the combined postpolypectomy surveillance literature is nothing less than dramatic (45). Major objections to colonoscopy include the need for sedation, the associated risks of sedation and the relatively high risk of perforation and postpolypectomy bleeding. Furthermore, the charges in several countries, including the United States, are in considerable excess of the true costs. The technology of endoscopy has continued to advance over the past 10 years, while guaiac testing and barium enema technology have made only limited strides.
Colonoscopy can now be performed by experts in many cases without sedation $(46,47)$, although the practice is widespread in some countries (48) but not in the United States. Perforation from diagnostic colonoscopy has been less than one in 3000 in studies published in the 1990s $(5,49,50)$. Complications associated with polypectomy are inevitable during colonoscopy and can be only partly reduced by proper technique. Because colonoscopy detects more polyps than other modalities, there will continue to be a higher complication rate associated with its use. However, to the extent that any initial strategy identifies colon polyps, it leads to colonoscopy. Therefore, to the extent that other strategies effectively identify polyps, they do not avoid the complications of colonoscopy and polypectomy.

\section{FAMILY HISTORY OF COLORECTAL NEOPLASIA LESS THAN HNPCC}

Persons with even one first degree relative with colorectal cancer incur about a twofold increased lifetime risk of developing colorectal cancer (51-54). Both the risk of colorectal cancer and the prevalence of adenomas at screening appear to be increased in persons with multiple first degree relatives with either cancer or adenoma (55), or persons with relatives diagnosed at a young age (younger than 60 years) with cancer or adenoma. The AHCPR guidelines recommend that persons with a first degree relative who has colorectal cancer or with adenomatous polyps at age younger than 60 years should be offered the same menu of options as average-risk persons but that screening should begin at age 40 years. The basis for this recommendation is that the incidence of colorectal cancer in such persons at age 40 years appears to be similar to the average-risk population risk at age 50 years (1). The guidelines state that "if the close relative was diagnosed with colorectal cancer before the age of 55 years or with an adenomatous polyp before age 60 years, special efforts should be made to assure that screening takes place". The guidelines of the ACS differ in some regards. In persons with a single first degree relative with cancer or adenomatous polyps diagnosed after age 60 years, or with relatives (ie, second or higher degree relatives) with colorectal cancer, the recommendation is that average-risk options be offered to the patient and that the physician may consider screening before the age of 50 years. If however, there is colorectal cancer or adenomas in a first degree relative younger than 60 years of age or in two or more first degree relatives, the ACS recommends total colon evaluation (TCE). TCE comprises either colonoscopy or DCBE, and the recommended interval of examination is five years. The ACS guidelines are preferred because they provide for TCE in patients with a higher risk family history. The unfortunate aspect of the ACS guidelines is the presentation of colonoscopy and DCBE as equivalent, which is hardly the case (56). In addition, there are no data on the use of DCBE in this population, whereas at least cross-sectional studies are available for colonoscopy (see above). Furthermore, the ACS guidelines state that DCBE can be performed without flexible sigmoidoscopy, despite clear evidence in the literature of major deficiencies of 
DCBE in the rectosigmoid colon (57-59). Table 4 shows results from my own practice with regard to persons with a positive family history.

\section{HNPCC}

HNPCC is characterized by the development of colorectal cancer at an early age, with a tendency toward right-sided lesions. The syndrome has autosomal dominant inheritance and results from germline mutations in one of four mismatch repair genes. Cancers also occur in a number of other organs, particularly the female genital tract. Identification of affected kindreds can be difficult because there is no absolute definition. A history with high predictive value for a mismatch repair mutation is shown in Table 5 . However, lesser histories of colorectal cancer may be present, particularly if cancers have occurred in other organs. Therefore, taking a detailed family history is necessary to identify adequately HNPCC kindreds. Traditional screening is by colonoscopy every two years beginning at age 20 years and continuing until age 40 years, and annually thereafter. This is the only group other than persons with ulcerative colitis for whom annual colonoscopy is still appropriate. Genetic testing is available and is typically effective in about $50 \%$ of kindreds (60). When a family history is identified, genetic testing should be offered in the context of genetic counselling.

\section{FAMILIAL ADENOMATOUS POLYPOSIS}

Familial adenomatous polyposis accounts for less than $1 \%$ of the colorectal cancer burden in the United States. A detailed description of this syndrome is not provided here. When a proband is identified, genetic testing should be offered in conjunction with a genetic counsellor. The genetic test is positive in about $80 \%$ of probands (61). It can then be

\section{REFERENCES}

1. Winawer SJ, Fletcher RH, Miller L, et al. Colorectal cancer screening: clinical guidelines and rationale. Gastroenterology 1997;112:594-642.

2. Byers T, Levin B, Rothenberger D. American Cancer Society guidelines for screening and surveillance for early detection of colorectal polyps and cancer: update 1997. American Cancer Society Detection and Treatment Advisory Group on Colorectal Cancer. CA Cancer J Clin 1997;47:154-60.

3. Report of the US Preventive Services Task Force. Guide to Clinical to Preventive Services. Baltimore: Williams and Wilkins, 1989.

4. US Preventive Services Task Force: Guide to Clinical Preventive Services: Report of the US Preventive Services Task Force, 2nd edn. Washington: Government Printing Office, 1996.

5. Mandel JS, Bond JH, Church TR, et al. Reducing mortality from colorectal cancer by screening for fecal occult blood. Minnesota Colon Cancer Control Study. N Engl J Med 1993;328:1365-71.

6. Kronborg O, Fenger C, Olsen J, Jorgensen OD, Sondergaard O. Randomized study of screening for colorectal cancer with faecal-occult-blood test. Lancet 1996;348:1467-71.

7. Hardcastle JD, Chamberlain JO, Robinson MH, et al. Randomized control trial of faecal-occult-blood screening for colorectal cancer. Lancet 1996;348:1472-7.

8. Leard LE, Savides TJ, Ganiats TG. Patient preferences for colorectal cancer screening. J Fam Pract 1997;45:211-8.

9. Selby JV, Friedman GD, Quesenberry CP Jr, Weiss NS. Effective fecal occult blood testing and mortality from colorectal cancer. A case-control study. Ann Intern Med 1993;118:1-6.

10. Selby JV, Friedman GD, Quesenberry CP Jr, Weiss NS. A case control study of screening sigmoidoscopy and mortality from colorectal cancer. N Engl J Med 1992;326:653-7.

11. Newcomb PA, Norfleet RG, Storer BE, Surawicz TS, Marcus PM.
TABLE 5

Amsterdam criteria for identification of a hereditary nonpolyposis colon cancer kindred

Three relatives with colorectal cancer

Colorectal cancer spans two generations

One relative diagnosed at age younger than 50 years

One relative is first degree relative of the other two

used with complete accuracy to identify family members who are affected. Family members who test positive or all family members in a kindred in whom the genetic test is negative should undergo flexible sigmoidoscopy on a yearly basis beginning at puberty. If the proband's genetic test is positive, family members with a negative genetic test can be screened according to average-risk guidelines.

\section{CONCLUSIONS}

For average-risk individuals, the current guidelines create a menu of options that differ with respect to effectiveness, up front costs and risk. The choice of test depends on the relative importance placed on these factors by patients, physicians and payers.

Persons with certain family histories of either colorectal cancer or adenomas are at substantially increased risk, and should be screened with colonoscopy at an earlier age and more frequent intervals than the average-risk person. Genetic testing is a consideration only when individuals are identified who have either the familial adenomatous polyposis phenotype or a combination of personal and family history with high predictive value for a mismatch repair mutation (HNPCC).

Screening sigmoidoscopy and colorectal cancer mortality. J Natl Cancer Inst 1992;84:1572-5.

12. Rex DK. Screening for colorectal cancer and polyps in average-risk persons. In: Schapiro M, Lehman GA, eds. Flexible Sigmoidoscopy Techniques and Utilization. Baltimore: Williams \& Wilkins, 1990:185-96.

13. Rex DK, Lehman GA, Ulbright TM, et al. Colonic neoplasia in asymptomatic persons with negative fecal occult blood tests: influence of age, gender, and family history. Am J Gastroenterol 1993;88:825-31.

14. Johnson DA, Gurney MS, Volpe RJ, et al. A prospective study of the prevalence of colonic neoplasms in asymptomatic patients with an age-related risk. Am J Gastroenterol 1990;85:969-74.

15. Foutch PG, Mai H, Pardy K, DiSario JA, Manne RK, Kerr D. Flexible sigmoidoscopy may be ineffective for secondary prevention of colorectal cancer in asymptomatic, average-risk men. Dig Dis Sci 1991;36:924-8.

16. Lieberman DA, Smith FW. Screening for colon malignancy with colonoscopy. Am J Gastroenterol 1991;86:946-51.

17. Rogge JD, Elmore MF, Mahoney SJ, et al. Low cost, office-based, screening colonoscopy. Am J Gastroenterol 1994;89:1775-80.

18. Baker JW, Gathright JB Jr, Timmcke AE, Hicks TC, Ferrari BT, Ray JE. Colonoscopic screening of asymptomatic patients with a family history of colon cancer. Dis Colon Rectum 1990;33:926-30.

19. Grossman S, Milos ML. Colonoscopic screening of person with suspected risk factors for colon cancer. Gastroenterology 1988;94:395-400.

20. Gryska PV, Cohen AM. Screening asymptomatic patients with high risk for colon cancer with full colonoscopy. Dis Colon Rectum 1992;35:523-9. 
21. Guillem JG, Forde KA, Treat MR, Neugut AI, O'Toole KM, Diamond BE. Colonoscopic screening for neoplasms in asymptomatic first-degree relatives of colon cancer patients. A controlled, prospective study. Dis Colon Rectum 1992;35:523-9.

22. Luchtefeld MA, Syverson D, Solfelt M, et al. Is colonoscopic screening appropriate in asymptomatic patients with family history of colon cancer? Dis Colon Rectum 1991;34:763-8.

23. McConnell JC, Nizin JS, Slade MS. Colonoscopy in patients with a primary family history of colon cancer. Dis Colon Rectum 1990;33:105-7.

24. Meagher AP, Stuart M. Colonoscopy in patients with a family history of colorectal cancer. Dis Colon Rectum 1992;35:315-21.

25. Orrom WJ, Brzezinski WS, Wiens EW. Heredity and colorectal cancer: A prospective, community-based, endoscopic study. Dis Colon Rectum 1990;33:490-3.

26. Rozen P, Roin E. A cost analysis of screening methodology for family members of colorectal cancer patients. Am J Gastroenterol 1989;84:1548-51.

27. Gaglia P, Atkins WS, Whitelaw S, et al. Variables associated with the risk of colorectal adenomas in asymptomatic patients with a family history of colorectal cancer. Gut 1995;36:385-90.

28. Bazzoli F, Fossi S, Sottili S, et al. The risk of adenomatous polyps in asymptomatic first-degree relatives of persons with colon cancer. Gastroenterology 1995;109:783-8.

29. Lanspa SJ, Lynch HT, Smyrk TC, et al. Colorectal adenomas in the Lynch syndromes. Results of a colonoscopy screening program. Gastroenterology 1990;98:1117-22.

30. Love RR, Morrissey JF. Colonoscopy in asymptomatic individuals with a family history of colorectal cancer. Arch Intern Med 1984;144:2209-11.

31. Vansen HFA, Jafer FCA, Memko FH. Screening for hereditary non-polyposis colorectal cancer: A study of 22 kindreds in the Netherlands. Am J Med 1989;86:278-81.

32. Lanspa SJ, Jenkins JX, Cavalieri J, et al. Surveillance in Lynch syndrome: How aggressive? Am J Gastroenterol 1994;89:1978-80.

33. Järvinén HJ, Mecklin JP, Sistonen P. Screening reduces colorectal cancer rate in families with hereditary nonpolyposis colorectal cancer. Gastroenterology 1995;108:1405-11.

34. Johnson CD, Ilstrup DM, Fish NM, et al. Barium enema: detection of colonic lesions in a community population. AJR Am J Roentgenol 1996;167:39-43.

35. Rex DK, Lehman GA, Ulbright TM, Smith JJ, Hawes RH. The yield of a second screening flexible sigmoidoscopy in average-risk persons after one negative examination. Gastroenterology 1994;106:593-5.

36. Rex DK, Cummings OW, Helper DJ, et al. 5-year incidence of adenomas after negative colonoscopy in asymptomatic average-risk persons. Gastroenterology 1996;111:1178-81.

37. Lieberman DA. Cost-effectiveness model for colon cancer screening. Gastroenterology 1995;109:1781-90.

38. Ransohoff DF, Lang CA. Screening for colorectal cancer with the fecal occult blood tests: a background paper. Ann Intern Med 1997;126:811-22.

39. Rex DK, Rahmani EY, Haseman JH, Lemmel GT, Kaster S, Buckley JS. Relative sensitivity of colonoscopy and barium enema for detection of colorectal cancer in clinical practice. Gastroenterology 1997;112:17-23.
40. Lemmel GT, Haseman JH, Rex DK, Rahmani E. Neoplasia distal to the splenic flexure in persons with proximal colon cancer. Gastrointest Endosc 1996;44:109-11.

41. Office of Technology Assessment. Cost-effectiveness of Colorectal Cancer Screening in Average-Risk Adults. Washington: United States Congress, 1995.

42. Zauber A. Presentation at Digestive Disease Week, New Orleans, May 1994.

43. Winawer SJ, Zauber AG, Ho MN, et al. Prevention of colorectal cancer by colonoscopic polypectomy. The National Polyp Study Workgroup. N Engl J Med 1993;329:1977-81.

44. Jørgensen OD, Kronborg O, Fenger C. The Funen adenoma follow-up study: Incidence and death from colorectal carcinoma in an adenoma surveillance program. Scand J Gastroenterol 1993;28:869-74.

45. Rex DK. Colonoscopy: A review of its yield for cancer and adenomas by indication. Am J Gastroenterol 1995;3:353-65.

46. Herman FN. Avoidance of sedation during total colonoscopy. Dis Colon Rectum 1990;33:70-2.

47. Seow-Choen F, Leong AFPK, Tsang CH. Selective sedation for colonoscopy. Gastrointest Endosc 1994;40:661-4.

48. Ristikankare MKO, Julkenen RJK. Pre-medication for gastrointestinal endoscopy as a rare practice in Finland: a nation wide survey. Gastrointest Endosc 1998;47:204-7.

49. Waye JD, Lewis BS, Yessayan S. Colonoscopy: a prospective report of complications. J Clin Gastroenterol 1992;15:347-51.

50. Basson MD, Etter L, Panzini LA. Rates of colonoscopic perforation in current practice. Gastroenterology 1998;114:1115.

51. St John DJ, McDermott FT, Hopper JL, Debney EA, Johnson WR, Hughes ES. Cancer risk in relatives of patients with common colorectal cancer. Ann Intern Med 1993;118:785-90.

52. Lovett E. Family studies in cancer of the colon and rectum. Br J Surg 1976;63:13-8.

53. Macklin MT. Inheritance of cancer of the stomach and large intestine in man. J Natl Cancer Inst 1960;224:551-71.

54. Woolf CM. A genetic study of carcinoma of the large intestine. Am J Hum Genet 1958;10:42-7.

55. Winawer SJ, Zauber AG, Gerdes H, et al. Risk of colorectal cancer in the families of patients with adenomatous polyps: National Polyp Study Workgroup. N Engl J Med 1996;334:82-7.

56. Rex DK. Barium enema 1995: Where are we now? Endoscopy 1995;27:200-2.

57. Kewenter J, Breging H, Engarås B, et al. Value of flexible sigmoidoscopy and double-contrast barium enema in the diagnosis of neoplasms in the rectum and colon in subjects with a positive hemoccult: results of 1831 rectosigmoidoscopies and double-contrast barium enemas. Endoscopy 1995;27:501-3.

58. Vellacott KD, Amar SS, Hardcastle JD. Comparison of rigid and flexible sigmoidoscopy with double contrast barium enemas. Br J Surg 1982;69:399-400.

59. Williams CB, Macrae FA, Bartram CI. A prospective study of diagnostic methods in adenoma follow-up. Endoscopy 1982;14:74-5.

60. Luce MC, Marr AG, Chauhan DP, et al. In vitro transcription/ translation assay for the screening of hMLH1 and hMSH2 mutations in familial colon cancer. Gastroenterology 1995;109:1368-74.

61. Powell SM, Petersen GM, Krush AJ, et al. Molecular diagnosis of familial adenomatous polyposis. N Engl J Med 1993;329:1982-7. 




The Scientific World Journal
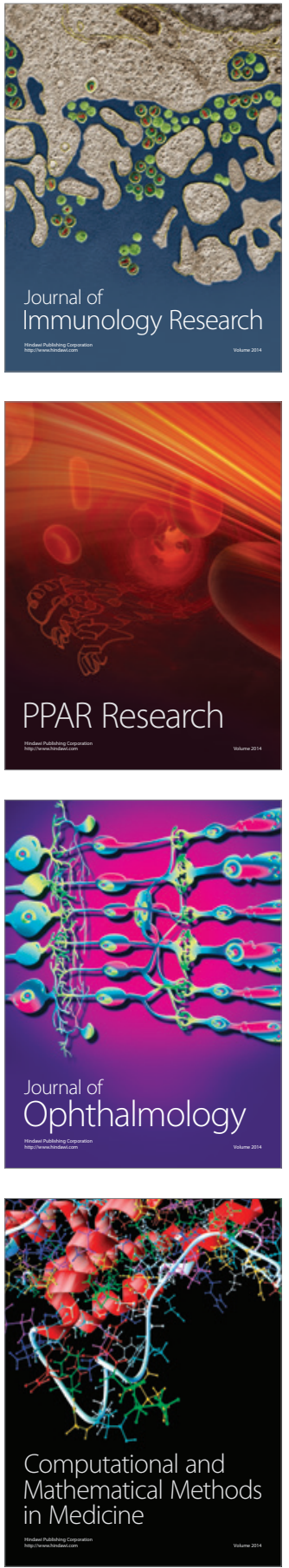

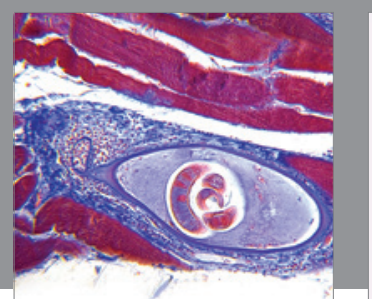

Gastroenterology Research and Practice

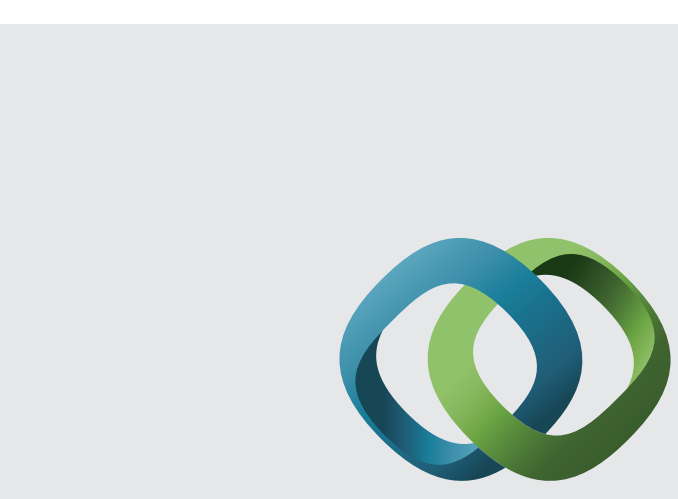

\section{Hindawi}

Submit your manuscripts at

http://www.hindawi.com

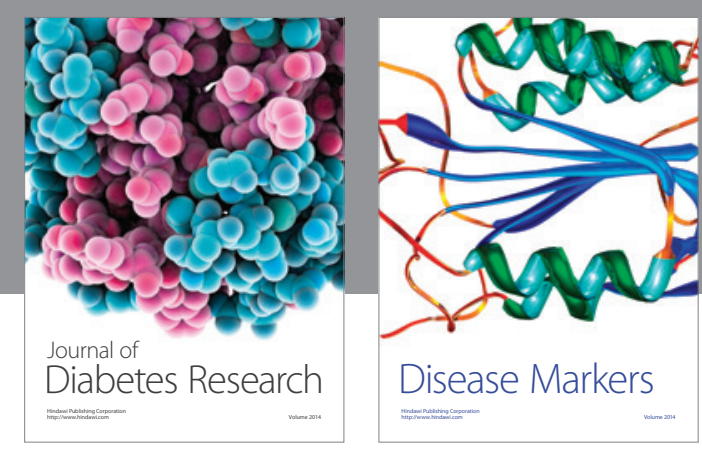

Disease Markers
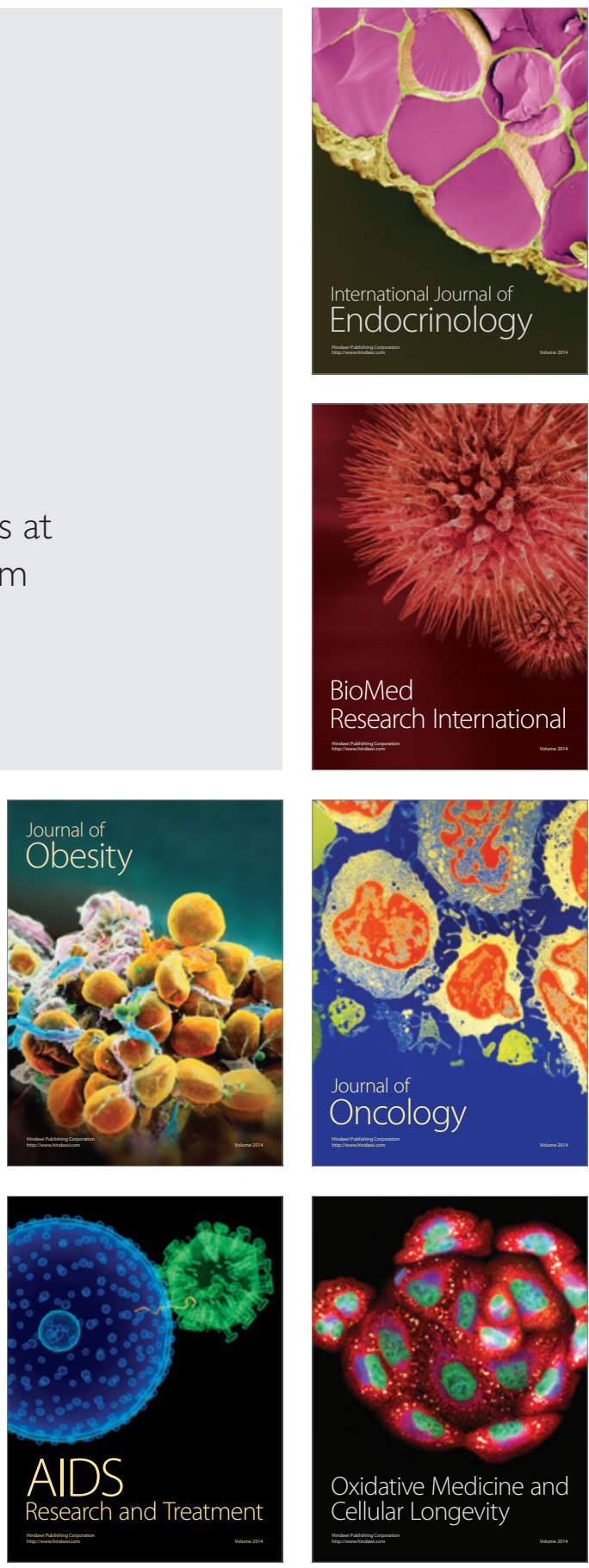